\title{
Article
}

\section{Solvent-free Temperature-Facilitated Direct Extrusion 3D Printing for Pharmaceuticals}

Kuzminska, Magda, Pereira, Beatriz, Habashy, Rober, Peak, Matthew, Isreb, Mohammad, Gough, Tim D, Isreb, Abdullah and Alhnan, Mohamed A

Available at http://clok.uclan.ac.uk/36809/

Kuzminska, Magda, Pereira, Beatriz, Habashy, Rober, Peak, Matthew, Isreb, Mohammad, Gough, Tim D, Isreb, Abdullah ORCID: 0000-0001-9939-6161 and Alhnan, Mohamed A (2021) Solvent-free Temperature-Facilitated Direct Extrusion 3D Printing for Pharmaceuticals. International Journal of Pharmaceutics . ISSN 1873-3476

It is advisable to refer to the publisher's version if you intend to cite from the work. http://dx.doi.org/10.1016/j.ijpharm.2021.120305

For more information about UCLan's research in this area go to http://www.uclan.ac.uk/researchgroups/ and search for <name of research Group>.

For information about Research generally at UCLan please go to http://www.uclan.ac.uk/research/

All outputs in CLoK are protected by Intellectual Property Rights law, including Copyright law. Copyright, IPR and Moral Rights for the works on this site are retained by the individual authors and/or other copyright owners. Terms and conditions for use of this material are defined in the policies page.

\section{CLoK}

Central Lancashire online Knowledge www.clok.uclan.ac.uk

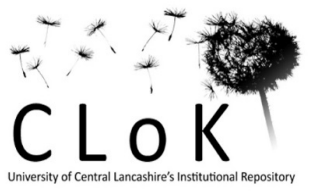




\section{Temperature-Facilitated Direct Extrusion 3D Printing for Pharmaceuticals.}

Magda Kuźmińska ${ }^{1,2}$, Beatriz Pereira ${ }^{1}$, Rober Habashy ${ }^{1}$, Matthew Peak ${ }^{3}$, Abdullah Isreb ${ }^{1}$, Mohammad Isreb, Tim D Gough, Mohamed A Alhnan**

${ }^{1}$ School of Pharmacy and Biomedical Sciences, University of Central Lancashire, Preston, Lancashire, UK

2 School of Pharmacy and Biomedical Sciences, University of Central Lancashire, Preston, Lancashire, UK; Faculty of Pharmacy with the Laboratory Medicine Division, Medical University of Warsaw, Warsaw, Poland

${ }^{3}$ Institute of Pharmaceutical Sciences, King's College London, London, UK.

${ }^{4}$ School of Pharmacy and Medical Sciences. University of Bradford UK

${ }^{5}$ Centre for Pharmaceutical Engineering Sciences, University of Bradford UK 


\begin{abstract}
In an era moving towards digital health, 3D printing as successfully proven its applicability in providing personalising medicine through a technology-based approach. Among the different 3D printing techniques, semisolid extrusion has shown its suitability in producing robust solid dosage forms, however, it usually requires the incorporation of a solvent (usually water), which may compromise the integrity of moisture sensitive drug molecules.

Here we demonstrate a new approach that simplifies semisolid extrusion 3D printing process with elimination of the post-printing drying step, by adding glyceryl monostearate (GMS). This component allowed 3D printing at relatively low temperature $\left(80-110{ }^{\circ} \mathrm{C}\right)$ of Eudragit RL/RS-based tablets, with rapid solidification at room temperature. The elimination of solvent will allow the incorporation of moisture sensitive active substances. Customization of the Eudragit RL:RS ratio allowed control of theophylline release profile.
\end{abstract}




\section{Introduction}

The increasing trend towards individualised medicine in healthcare led to exploring the potential of several 3D printing techniques as an on-demand manufacturing tool of solid dosage forms $(1,2)$. Among these, fused deposition modelling (FDM) 3D printing has been an extensively researched approach, owing to its low cost, lack of drying and/or finishing steps and accounting on an established technique of Hot Melt Extrusion (HME) for producing filaments (3-5). Several attempts were carried out to reduce the thermal stress associated with this technology through the use of plasticisers $(6,7)$ and low melting/glass transition temperature polymers (8). Nevertheless, the need of pre-printing fabrication of drug-loaded filaments drove the effort toward finding a more simplified fabrication process that facilitate and shorten the thermal exposure of both active ingredient and excipients.

Semi-solid extrusion is a 3D printing technology that consists of extrusion of semi-solid materials such as pastes $(9,10)$ and gels $(11)$ through a defined size nozzle to create a new structure after solidification (e.g. tablets). The use of a such technique eliminates the need of an intermediate step of filament manufacturing prior to $3 \mathrm{D}$ printing. Semi-solid extrusion has been used to demonstrate the feasibility of producing multidrug solid dosage forms with individualised drug-release profile $(16,17)$. Later, work demonstrated the applicability of the same technology to manufacture gastro-floating tablets (18), doseflexible systems with immediate-release profile (19) and orodispersible films (20). In addition, it avoids a high processing temperature, thus poses an attractive alternative to FDM. However, the starting materials and their mixing ratios should be carefully considered to meet required strict rheological properties that allows a smooth, reproducible and efficient extrusion which can solidify following 3D printing completion $(12,13)$. In most cases, solvent (often water) is used to facilitate material flow through reducing the viscosity of the mixture (14). However, this approach opens up the door for two challenges; the inclusion of an additional drying step for the printed product (quality and logistic issues associated with it), and the risk of drug degradation mainly due to hydrolysis. More recently, we have reported a hybrid approach of combining both solvent and temperature to produce immediate and extended release tablets at a relatively moderate temperature (15).

A more simplified process that avoiding a post-printing process is needed, HPC-based tablets with immediate (21) and sustained release profiles (22) were produced by using elevated temperature and 
pneumatic or screw-based extrusion. An alternative solution was the use of a low melting carrier (e.g. PEG4000, melting point of approximately $65^{\circ} \mathrm{C}$ ) to fabricate immediate-release tablets (23).

In this work, we report the use of semi-solid extrusion as a single 3D printing step. We also report the novel use of fatty glyceride (glycerol monostearate) as both lubricant and solidifying agent. GMS is a poorly water soluble excipient used in food, cosmetic and pharmaceutical applications for its emollient, emulsifier and plasticiser properties (28). In solid dosage forms, it is usually added as a lubricant (29) or a sustained-release matrix (30-32). Eudragit ${ }^{\circledR} \mathrm{RL}$ and $\mathrm{RS}$ are insoluble poly(meth)acrylates with $\mathrm{pH}$ independent swelling hydration behaviour with high and low water permeability, respectively (24). These have been widely used in combination for customisation of drug release profile (25), including using FDM 3D printing $(26,27)$.

\section{Materials and methods}

\subsection{Materials}

Theophylline was obtained from Acros Organics (UK). Eudragit ${ }^{\circledR}$ RL100 and RS100 were donated by Evonik (Darmstadt, Germany). Triethyl citrate (TEC) was obtained from Sigma-Aldrich (Dorset, UK). Glyceryl monostearate (GMS) (Imwittor K900) was a donation from IOI Oleo GmbH (Germany).

\subsection{Hansen Solubility Parameters (HSP) calculations}

Functional group contribution method was used to calculate the HSP values of the API and excipients. HSPiP software (version 5.3.03) was used to calculate the $\delta \mathrm{D}$ (Dispersion component), $\delta \mathrm{P}$ (Polar component, $\delta \mathrm{H}$ (Hydrogen-bonding component) and $\delta \mathrm{T}$ (Total) using the canonical SMILE of each compound.

\subsection{Rheological Studies}

Advanced Capillary Rheometer RH10 (Bohlin Instruments, UK) was used to assess the extensional rheology of the mixtures presented in Table I. Physical mixtures of Eudragit RL100, and blends with theophylline, GMS and TEC were fed into the two barrels of the rheometer each fitted with a $1 \mathrm{~mm}$ die 
(one long die and one orifice die). The barrel was heated to $110^{\circ} \mathrm{C}$ for $10 \mathrm{~min}$ before the experiment started. The formulations were subjected to two precompression stages at $0.5-1 \mathrm{MPa}$. The test was carried out at a shearing rate of $20,50,100 \mathrm{~S}^{-1}$. The shear and extensional viscosity for each of the above formulations was calculated.

\subsection{Preparation of the feed for semi solid extrusion}

The prepared formulations with the required mixing ratios of materials are highlighted in Table II. The methacrylate polymer(s), GMS and theophylline were accurately weighed and mixed using a mortar and pestle. The blends were then transferred to a Krups F20342 grinder (Germany) where it was shear-mixed with TEC. Blends (approximately $10 \mathrm{~g}$ ) were filled in a $12 \mathrm{~mm}$ diameter metal syringe (Hyrel 3D, Atlanta, USA) to be printed as described in Section 2.5.

\subsection{Tablet design and $3 D$ printing}

Cylindrical shaped tablets (diameter: $13 \mathrm{~mm}$, height: $3 \mathrm{~mm}$ ) were designed using Autodesk $^{\circledR}$ 3ds Max Design 2019 (Autodesk, Inc., USA). The designs were imported to the Slic3r (version 1.3) software in stereolithographic (STL) format. The latter were then converted to gcode files using the following settings: first layer thickness: $0.6 \mathrm{~mm}$, layer thickness: $0.3 \mathrm{~mm}$, speed perimeters: $50 \%$, infill speed: $8 \mathrm{~mm} / \mathrm{sec}$, first layer build speed: $6 \mathrm{~mm} / \mathrm{sec}$ and travel speed: $15 \mathrm{~mm} / \mathrm{sec}$. The nozzle and filament diameters were set as $1.194 \mathrm{~mm}$.

A Hyrel System 30M (Hyrel 3D, Atlanta, USA) equipped with a VOL-25 (Volcano) modular head and a 16-gauge stainless steel tip was used to manufacture the tablets. The standard glass plate was covered with an acrylic sheet to achieve a better adhesion of the printed layers to the base plate. The following settings were used for the Repetrel software (version 3.0) for the printer head: infill percentage: $100 \%, \mathrm{Z}$ layer thickness: 0.3 , motor pulses rate: 2.3 pulses $/ \mathrm{nL}$ and a material flow multiplier of $0.8 \mathrm{~mm}$. Prior to 3D printing, the syringe body was placed in an aluminium heated sleeve/housing where the feed was heated for $30 \mathrm{~min}$.

\subsection{Thermal analysis}


Raw materials and samples of the 3D printed tablets were analysed by thermogravimetric analysis (TGA) and differential scanning calorimetry (DSC). Samples of approximately $10 \mathrm{mg}$ were scanned in triplicate in platinum pans using a TGA Q500 (TA Instruments, Elstree, Hertfordshire, UK). Samples were heated at a rate of $10^{\circ} \mathrm{C} / \mathrm{min}$ from $25^{\circ} \mathrm{C}$ to $500^{\circ} \mathrm{C}$ with a nitrogen purge of $40: 60 \mathrm{~mL} / \mathrm{min}$ for furnace: sample, respectively. Samples $(\sim 5 \mathrm{mg})$ were scanned in triplicate in standard aluminium pans at a rate of $10^{\circ} \mathrm{C} / \mathrm{min}$ from $0^{\circ} \mathrm{C}$ to $300^{\circ} \mathrm{C}$, with a nitrogen purge of $50 \mathrm{~mL} / \mathrm{min}$, using a DSC Q2000 (TA Instruments, Elstree, UK). TA Universal analysis software (v 4.5A, TA Instruments, Elstree, UK) was used to analyse data for both TGA and DSC.

\subsection{X-Ray Powder Diffractometry (XRPD)}

The physical form of the drug and excipients within the 3D printed tablets was assessed using a powder X-ray diffractometer, D2 Phaser with Lynxeye (Bruker, Germany). Samples were scanned from 2 Theta $=5^{\circ}$ to $50^{\circ}$ using a $1.25 \mathrm{~s}$ time count and $0.01^{\circ}$ step width. The divergence slit was $1 \mathrm{~mm}$ and the scatter slit was $0.6 \mathrm{~mm}$. The filament emission was $10 \mathrm{~mA}$ with a scan type coupled with a theta/theta scintillation counter over $60 \mathrm{~min}$. A voltage of $30 \mathrm{kV}$ was used, the wavelength was $0.154 \mathrm{~nm}$ using $\mathrm{Cu}$ source and a voltage of $30 \mathrm{kV}$.

\subsection{Characterization of the $3 D$ printed tablets}

The mechanical properties of the 3D printed tablets were assessed by measuring tablet hardness using an Agilent 200 Tablet Hardness Tester (Agilent Technologies, Germany). The test was done in triplicate. A digital calliper (eSYNic, China) was used to measure the radius and the thickness of the tablets. The weight uniformity of the 3D printed tablets was determined by weighing approximately 10 tablets randomly selected from each preparation. The average mass, standard deviation and percentage deviation from average mass were determined for each batch.

\subsection{Analysis of drug content using HPLC}

The drug content of the 3D printed tablets was assessed using an Agilent 1260 series UV-HPLC (Agilent Technologies, Germany) with XTerra RP 18 column $(150 \times 4.6 \mathrm{~mm}, 5 \mu \mathrm{m}$ 
particle size) (Waters, Ireland) as previously described (6). The injection volume was $5 \mu \mathrm{L}$ and the mobile phase used consisted of $10 \mathrm{mM}$ ammonium acetate buffer: methanol: acetonitrile (86:7:7). The analysis was carried out at a flow rate of $1 \mathrm{~mL} / \mathrm{min}$, at $40^{\circ} \mathrm{C}$, with a run time of $7 \mathrm{~min}$ and wavelength of $272 \mathrm{~nm}$.

\subsection{Scanning Electron Microscopy (SEM)}

The morphology of the external and cross-sectional surfaces of the 3D printed tablets were assessed using a JCM-6000 plus NeoScope ${ }^{\mathrm{TM}}$ microscope (Jeol, Tokyo, Japan) at $10 \mathrm{kV}$. All samples were gold coated prior to imaging using a JFC-1200 Fine Coater (Jeol, Tokyo, Japan). The images were collected using Image J software (v 1.2.0., Tokyo, Japan).

\subsection{In vitro dissolution}

The impact of the ratio of polymers used on the release profile of theophylline was assessed using a USP II dissolution test paddle apparatus (Erweka GmbH, Germany). Each experiment was carried out in triplicate at $37 \pm 0.5^{\circ} \mathrm{C}$ with a paddle speed of $50 \mathrm{rpm}$. The tablets were tested in $750 \mathrm{~mL}$ of $0.1 \mathrm{M} \mathrm{HCl}(\mathrm{pH} 1.2)$ for $2 \mathrm{~h}$, followed by $4 \mathrm{hrs}$ exposure to $\mathrm{pH} 6.8$ phosphate buffer (through the addition of $250 \mathrm{~mL}$ of tribasic phosphate solution $0.215 \mathrm{M}$ ). Data was collected each 5 min by an UV/VIS spectrophotometer (PG Instruments Limited, UK) at a wavelength of $272 \mathrm{~nm}$ and a path length of $1 \mathrm{~mm}$. Data were analysed using IDISis software version 2012 (Automated Lab, Berkshire, UK).

\subsection{Statistical analysis}

One-way ANOVA was employed using SPSS Software (22.0.0.2) to analyse the results. Differences in results above probability level $(p<0.05)$ was considered significant. 


\section{Results and discussion}

A schematic diagram of the developed 3D printing process can be found in Fig. 1. In this process, a polymer-based pharmaceutical ink is loaded to a syringe cartridge at a set temperature. The raw materials can be loaded as compressed powder with a cylindric shape with the dimensions of the syringe (12 mm diameter x $60 \mathrm{~mm}$ height). In the future, single-use syringes could be used instead to avoid any cleaning step and contamination between formulation.

Initial screening of compatibility using Hansen solubility parameters indicates potential for good miscibility between the polymer, plasticiser (TEC) and GMS $\left(\delta \mathrm{T}<7 \mathrm{MPa}^{1 / 2}\right)($ Table III).

The shear and extensional viscosity of the polymer and various formulations was measured using extensional rheometer. The shear viscosity of Eudragit RL (as a model polymer) confirms its highly elastic nature at $110^{\circ} \mathrm{C}$ (Fig. 2A). In fact, the diameter difference between the extruded polymer from the long and orifice die due to die swelling was significant $(3.5 \mathrm{~mm}$ vs $5 \mathrm{~mm})(\mathbf{F i g}$. 3A). The extensional viscosity of the formulations detailed in Table I are presented in Fig. 2B. The incorporation of GMS into Eudragit RL maintained extensional viscosity $<10 \mathrm{kPa} . \mathrm{s}$. The figure shows that adding increasing concentrations theophylline (20 and $43 \% \mathrm{w} / \mathrm{w})$ resulted in higher extensional viscosity values. It is possible that the insoluble theophylline crystals added more elasticity to the formulation. TEC reduces the viscosity significantly. Overall, adding TEC and GMS to drug: polymer blend (the actual formulation used for producing the Eudragit RL tablets) has the lowest viscosity thanks to combination of the plasticiser and the glycerides (Fig. 2B). In fact, the extruded filaments have a significantly smaller diameter compared to the pure polymer (Fig. 3B) confirming the reduction in the elasticity of the sample.

The rheological behaviour of the initial polymer blend was reflected initial 3D printing trials. By using Eudragit RL or its blend with theophylline, no material could be extruded through the syringe. However, adding excess amount of plasticizer (TEC) allowed a facile flow of materials, yet it yielded flexible matrices unsuitable for 3D printing. GMS was then added to the formulation due to its thermal lubrication and rheological properties. The use of such combination (TEC and GMS) has been previously reported to facilitate hot melt extrusion (HME) of an Eudragit RS PO-based formulation 
(29). TEC demonstrated to lower both the Tg and melt viscosity of the polymer, while GMS acted only by decreasing its melt viscosity. The inclusion in the formulation contributed to a controlled flow of the material during extrusion. With a melting point at $58-65^{\circ} \mathrm{C}(33,34)$, it allows $3 \mathrm{D}$ printing at a relatively low temperature $\left(90-110^{\circ} \mathrm{C}\right)$, with a rapid solidification at room temperature without the need of a postprinting drying step.

TGA was performed to assess the stability of the raw materials at the processing temperatures (90-110 $\left.{ }^{\circ} \mathrm{C}\right)$. Eudragit RL and TEC showed $2 \%$ of weight loss up to $110^{\circ} \mathrm{C}($ Fig. 4) which is believed to be due to moisture evaporation, similarly to previous studies $(6,26)$. All components were stable at the $3 \mathrm{D}$ printing temperatures, confirming their suitability for the developed method. DSC thermographs of the 3D printed tablets showed an endotherm event at around $53-55{ }^{\circ} \mathrm{C}($ Fig. 4), which is believed to be the melting of GMS, indicating the presence of this component in crystalline form. Therefore, a printing temperature above $55^{\circ} \mathrm{C}$ deemed necessary to liquidate GMS crystals and allow successful 3D printing the formulation.

Following extrusion of the nozzle, the solidification of these matrix will then provide a stable polymeric layer that will withstand the weight of stacking layers. The shift of GMS melting from $63^{\circ} \mathrm{C}$ to lower temperatures, may be explained by the plasticising effect of TEC. A shift however, this could not be visualised on the DSC thermographs, probably due to the very low onset of the temperature. The presence of thermal events in the $3 \mathrm{D}$ printed tablets at $>200{ }^{\circ} \mathrm{C}$ could not be investigated due to sample degradation at high temperatures.

The XRPD pattern of the 3D printed tablets revealed diffraction peaks distinctive of theophylline at $2(\Theta)=7^{\circ}, 12^{\circ}, 14^{\circ}$ and $24^{\circ}$ (Fig. 6), indicating the presence of the drug in crystalline form. A subtle peak, which is believed to be characteristic of GMS, can be seen at $2(\Theta)=20^{\circ}$ (Fig. 6). This may indicate incomplete dissolution of GMS and the presence of crystals of this component within the polymeric matrix.

SEM images of the 3D printed showed a smooth glossy surface, similar to GMS-based films $(35,36)$, which can be explained by its lubricant characteristics. The tablets showed uniform layers 
$(300 \mu \mathrm{m})$ and in general, the cross-section images showed fusion between the layers (Fig. 7) The 3D printed tablets demonstrated friability properties pharmaceutically acceptable $(<1 \%)(37)$ and a high resistance to crushing force values that were not significantly different between formulations $(p>0.05)$

(Table IV).

Customizing theophylline release was achieved by manipulating the methacrylate polymer ratios: Eudragit RL: RS ratio (Fig. 8). By increasing content of Eudragit RS, led to further delay of theophylline release from the matrix structure. This may be explained by the lower number of quaternary ammonium groups of Eudragit RL when compared with Eudragit RL (38). These groups provide higher hydrophilicity, promoting more intense interaction within the polymeric matrix, explaining the higher permeability of the polymer $(39,40)$.

The mechanism of drug release from Eudragit RL and RS-based drug delivery systems has been proposed to take place through the control of fluid permeation and consequent dissolution and diffusion of the drug $(41,42)$. It has been shown that drug diffusion is $\mathrm{pH}$ independent, which can be explained by the ionisation of the quaternary ammonium groups of the polymers at all $\mathrm{pH}$ levels with the gastrointestinal tract. On the other hand, it is dependent of its size and steric effects (43), ionic strength and the buffer used in the dissolution medium $(44,45)$.

Although the developed pharmaceutical ink proved to be highly efficient in providing a lowtemperature solution and in avoiding pre- and post-printing processes, it is limited to extended-release dosage forms. Further advancement of the system is necessary to adapt it to immediate- and relayed release carriers. 


\section{Conclusions}

The presented approach provides a significant advancement for semi-solid extrusion. Rather than starting with aqueous semi-solids that risks API hydrolysis, the system enables a direct ink writing at moderate temperature range $80-110{ }^{\circ} \mathrm{C}$ with readily-available tablet without the need for finishing or drying steps. An important inventive solution of incorporating fatty glyceride as dual solidifying agent and lubricant. This glyceride facilitates semi-solid extrusions at lowered temperature and rapid solidification following layer formation. The system proved compatible with widely-used methacrylate polymer where modulation of the release profile of the model drug could be achieve by manipulating polymer permeability. 
1. M.A. Alhnan, T.C. Okwuosa, M. Sadia, K.W. Wan, W. Ahmed, and B. Arafat. Emergence of 3D Printed Dosage Forms: Opportunities and Challenges. Pharm Res. 33:1817-1832 (2016).

2. S. Pravinand A. Sudhir. Integration of 3D printing with dosage forms: A new perspective for modern healthcare. Biomedicine \& Pharmacotherapy. 107:146-154 (2018).

3. M. Alhijjaj, J. Nasereddin, P. Belton, and S. Qi. Impact of Processing Parameters on the Quality of Pharmaceutical Solid Dosage Forms Produced by Fused Deposition Modeling (FDM). Pharmaceutics. 11: (2019).

4. J. Skowyra, K. Pietrzak, and M.A. Alhnan. Fabrication of extended-release patient-tailored prednisolone tablets via fused deposition modelling (FDM) 3D printing. Eur J Pharm Sci. 68:11-17 (2015).

5. A. Melocchi, F. Parietti, A. Maroni, A. Foppoli, A. Gazzaniga, and L. Zema. Hot-melt extruded filaments based on pharmaceutical grade polymers for 3D printing by fused deposition modeling. International Journal of Pharmaceutics. 509:255-263 (2016).

6. T.C. Okwuosa, D. Stefaniak, B. Arafat, A. Isreb, K.W. Wan, and M.A. Alhnan. A Lower Temperature FDM 3D Printing for the Manufacture of Patient-Specific Immediate Release Tablets. Pharm Res. 33:2704-2712 (2016).

7. $\quad$ B.C. Pereira, A. Isreb, R.T. Forbes, F. Dores, R. Habashy, J.B. Petit, M.A. Alhnan, and E.F. Oga. 'Temporary Plasticiser': A novel solution to fabricate 3D printed patient-centred cardiovascular 'Polypill' architectures. Eur J Pharm Biopharm. 135:94-103 (2019).

8. G. Kollamaram, D.M. Croker, G.M. Walker, A. Goyanes, A.W. Basit, and S. Gaisford. Low temperature fused deposition modeling (FDM) 3D printing of thermolabile drugs. Int J Pharm. 545:144-152 (2018).

9. $\quad$ S.A. Khaled, J.C. Burley, M.R. Alexander, and C.J. Roberts. Desktop 3D printing of controlled release pharmaceutical bilayer tablets. Int J Pharm. 461:105-111 (2014).

10. M. Cui, H. Pan, D. Fang, S. Qiao, S. Wang, and W. Pan. Fabrication of high drug loading levetiracetam tablets using semi-solid extrusion 3D printing. Journal of Drug Delivery Science and Technology. 57:101683 (2020).

11. T. Tagami, M. Ando, N. Nagata, E. Goto, N. Yoshimura, T. Takeuchi, T. Noda, and T. Ozeki. Fabrication of Naftopidil-Loaded Tablets Using a Semisolid Extrusion-Type 3D Printer and the Characteristics of the Printed Hydrogel and Resulting Tablets. Journal of Pharmaceutical Sciences. 108:907-913 (2019).

12. Y. Cheng, H. Qin, N. Acevedo, and X. Shi. Development of methylcellulose-based sustainedrelease dosage by semisolid extrusion additive manufacturing in drug delivery system. Journal of Biomedical Materials Research Part B: Applied Biomaterials (2020).

13. Y. Yang, X. Wang, X. Lin, L. Xie, R. Ivone, J. Shen, and G. Yang. A tunable extruded 3D printing platform using thermo-sensitive pastes. International Journal of Pharmaceutics. 583:119360 (2020).

14. S.A. Khaled, M.R. Alexander, D.J. Irvine, R.D. Wildman, M.J. Wallace, S. Sharpe, J. Yoo, and C.J. Roberts. Extrusion 3D Printing of Paracetamol Tablets from a Single Formulation with Tunable Release Profiles Through Control of Tablet Geometry. AAPS PharmSciTech. 19:3403-3413 (2018).

15. F. Dores, M. Kuźmińska, C. Soares, M. Bohus, L. A Shervington, R. Habashy, B.C. Pereira, M. Peak, A. Isreb, and M.A. Alhnan. Temperature and solvent facilitated extrusion based 3D printing for pharmaceuticals. European Journal of Pharmaceutical Sciences. 152:105430 (2020).

16. S.A. Khaled, J.C. Burley, M.R. Alexander, J. Yang, and C.J. Roberts. 3D printing of tablets containing multiple drugs with defined release profiles. Int J Pharm. 494:643-650 (2015).

17. S. Khaled, J. Burley, M. Alexander, J. Yang, and C. Roberts. 3D printing of five-in-one dose combination polypill with defined immediate and sustained release profiles. Journal of controlled release : official journal of the Controlled Release Society. 217: (2015).

18. Q. Li, X. Guan, M. Cui, Z. Zhu, K. Chen, H. Wen, D. Jia, J. Hou, W. Xu, X. Yang, and W. Pan. Preparation and investigation of novel gastro-floating tablets with 3D extrusion-based printing. International Journal of Pharmaceutics. 535:325-332 (2018).

19. M. Cui, Y. Li, S. Wang, Y. Chai, J. Lou, F. Chen, Q. Li, W. Pan, and P. Ding. Exploration and Preparation of a Dose-Flexible Regulation System for Levetiracetam Tablets via Novel Semi- 
Solid Extrusion Three-Dimensional Printing. Journal of Pharmaceutical Sciences. 108:977-986 (2019).

20. T.T. Yan, Z.F. Lv, P. Tian, M.M. Lin, W. Lin, S.Y. Huang, and Y.Z. Chen. Semi-solid extrusion 3D printing ODFs: an individual drug delivery system for small scale pharmacy. Drug Dev Ind Pharm. 46:531-538 (2020).

21. M. Fanous, S. Gold, S. Muller, S. Hirsch, J. Ogorka, and G. Imanidis. Simplification of fused deposition modeling 3D-printing paradigm: Feasibility of 1-step direct powder printing for immediate release dosage form production. International Journal of Pharmaceutics. 578:119124 (2020).

22. A. Goyanes, N. Allahham, S.J. Trenfield, E. Stoyanov, S. Gaisford, and A.W. Basit. Direct powder extrusion 3D printing: Fabrication of drug products using a novel single-step process. International Journal of Pharmaceutics. 567:118471 (2019).

23. P. Li, H. Jia, S. Zhang, Y. Yang, H. Sun, H. Wang, W. Pan, F. Yin, and X. Yang. Thermal Extrusion 3D Printing for the Fabrication of Puerarin Immediate-Release Tablets. AAPS PharmSciTech. 21:20 (2019).

24. Evonik. EUDRAGIT® functional polymers for sustained release. https://healthcare.evonik.com/product/health-care/en/products/pharmaceutical-

excipients/time-controlled-release/ (accessed 08/06/2020.

25. A.R. Duarte, C. Roy, A. Vega-González, C.M. Duarte, and P. Subra-Paternault. Preparation of acetazolamide composite microparticles by supercritical anti-solvent techniques. Int J Pharm. 332:132-139 (2007).

26. K. Pietrzak, A. Isreb, and M.A. Alhnan. A flexible-dose dispenser for immediate and extended release 3D printed tablets. Eur J Pharm Biopharm. 96:380-387 (2015).

27. J. Krause, M. Bogdahn, F. Schneider, M. Koziolek, and W. Weitschies. Design and characterization of a novel 3D printed pressure-controlled drug delivery system. European Journal of Pharmaceutical Sciences. 140:105060 (2019).

28. R.S. Rowe, PJ; Quinn, Marian E. Handbook of Pharmaceutical Excipients Pharmaceutical Press, London, 2009.

29. Y. Zhu, N.H. Shah, A.W. Malick, M.H. Infeld, and J.W. McGinity. Influence of a lipophilic thermal lubricant on the processing conditions and drug release properties of chlorpheniramine maleate tablets prepared by hot-melt extrusion. Journal of Drug Delivery Science and Technology. 14:313-318 (2004).

30. K.K. Peh, C.F. Wong, and K.H. Yuen. Possible mechanism for drug retardation from glyceryl monostearate matrix system. Drug Dev Ind Pharm. 26:447-450 (2000).

31. D. Peri, S. Bogdansky, S. Allababidi, and J.C. Shah. Development of an Implantable, Biodegradable, Controlled Drug Delivery System for Local Antibiotic Therapy. Drug Development and Industrial Pharmacy. 20:1341-1352 (1994).

32. S. Laila, T. Haque, M. Talukder, I. Ahmed, M. Islam, and H. Rahman. Development of Glyceryl Monostearate Based Ciprofloxacin Hydrochloride Sustained Release Matrix Tablet: In vitro Study. Dhaka University Journal of Pharmaceutical Science. 8: (2009).

33. K.-O. Choi, J. Choe, S. Suh, and S. Ko. Positively Charged Nanostructured Lipid Carriers and Their Effect on the Dissolution of Poorly Soluble Drugs. Molecules. 21:672 (2016).

34. M. Qushawy, K. Prabahar, M. Abd-Alhaseeb, S. Swidan, and A. Nasr. Preparation and Evaluation of Carbamazepine Solid Lipid Nanoparticle for Alleviating Seizure Activity in Pentylenetetrazole-Kindled Mice. Molecules. 24:3971 (2019).

35. C.K. Rajsharad, Shivaji Pva based film coating and film coating compositions 2005.

36. T.P.T. Farrell, Jason; Friend, Barry ;Gulian, Scott Film coatings containing fine particle size detackifiers and substrates coated therewith 2010.

37. FDA. Q4B Evaluation and Recommendation of Pharmacopoeial Texts for Use in the ICH Regions: Annex 9(R1) Tablet Friability General Chapter Guidance for Industry https://www.fda.gov/media/77008/download (accessed 19/07/2020.

38. K. Lehmann. In Wasser dispergierbare, hydrophile Acrylharze mit abgestufter Permeabilität für diffusionsgesteuerte Wirkstoffabgabe aus Arzneiformen,. Acta Pharm Technol:146-152 (1986). 
39. M. Jelvehgariand S.H. Montazam. Comparison of microencapsulation by emulsion-solvent extraction/evaporation technique using derivatives cellulose and acrylate-methacrylate copolymer as carriers. Jundishapur J Nat Pharm Prod. 7:144-152 (2012).

40. F. Siepmann, J. Siepmann, M. Walther, R.J. MacRae, and R. Bodmeier. Polymer blends for controlled release coatings. J Control Release. 125:1-15 (2008).

41. B. Glaessl, F. Siepmann, I. Tucker, T. Rades, and J.Siepmann. Mathematical modeling of drug release from Eudragit RS-based delivery systems. Journal of Drug Delivery Science and Technology. 20:127-133 (2010).

42. P.A. Steward, J. Hearn, and M.C. Wilkinson. Studies on permeation through polymer latex films, I. Films containing no or only low levels of additives. Polymer International. 38:1-12 (1995).

43. K. Lehmann. Chemistry and application properties of polymethacrylate coating system, Marcel Dekker, New York, 1997.

44. R. Bodmeier, X. Guo, R.E. Sarabia, and P.F. Skultety. The influence of buffer species and strength on diltiazem $\mathrm{HCl}$ release from beads coated with the aqueous cationic polymer dispersions, Eudragit RS, RL 30D. Pharm Res. 13:52-56 (1996).

45. K. Wagnerand J. McGinity. Influence of chloride ion exchange on the permeability and drug release of Eudragit RS 30 D films. J Control Release. 82:385-397 (2002). 


\section{List of figures}

Fig. 1. (A) Set-up for semi-solid extrusion 3D printing. (a) The printer is equipped with a metal syringe surrounded by temperature-controlled heating jacket. The syringe is fitted with a luer-lock stainless steel needle (G18), (b) The pharmaceutical ink (compressed powder) is added. The ink is then extruded by a piston pushed by computer-controlled stepper motor equipped with gear to produce (c) 3D printed tablet. (B) Top and (C) side photographs of 3D printed tablets based on Eudragit RL: RS: 100:0, 75:25, 50:50, 25:75 and 0:100.

Fig. 5 (A) Shear viscosity of Eudragit RL 100 at temperature range of $90-110^{\circ} \mathrm{C}$, (B) Extensional viscosity data of mixtures.

Fig. 3 (A) Eudragit RL extruded at $110^{\circ} \mathrm{C}$ using a long die (left, d=3.5mm), and an orifice die (right, $\mathrm{d}=5 \mathrm{~mm}$ ) (B) Eudragit RL formulation extruded at $90^{\circ} \mathrm{C}$ using long die (left, $\mathrm{d}=1.5 \mathrm{~mm}$ ), and an orifice die (right, $\mathrm{d}=4 \mathrm{~mm}$ ).

Fig. 4 TGA thermal degradation profiles of raw theophylline, Eudragit RL, Eudragit RS, TEC, GMS, and 3D printed tablets based on Eudragit RL: RS: 100:0, 75:25, 50:50, 25:75 and 0:100.

Fig. 5 DSC thermograph of raw theophylline, Eudragit RL, Eudragit RS, TEC, GMS, and 3D printed tablets based on Eudragit RL: RS: 100:0, 75:25, 50:50, 25:75 and 0:100.

Fig. 6 XRD patterns of raw theophylline, Eudragit RL, Eudragit RS, TEC, GMS, and 3D printed tablets based on Eudragit RL: RS: 100:0, 75:25, 50:50, $25: 75$ and 0:100.

Fig. 6 (A) Eudragit RL filaments extruded at $110^{\circ} \mathrm{C}$, Using long die $(\mathrm{d}=3.5 \mathrm{~mm})$, right: using orifice die $(\mathrm{d}=5 \mathrm{~mm})(\mathbf{B})$ mixture 2 filament extruded at $90^{\circ} \mathrm{C}$ Left: Using long die $(\mathrm{d}=1.5 \mathrm{~mm})$, right: using orifice die $(\mathrm{d}=4 \mathrm{~mm})$.

Fig. 7 SEM images of side-view (A1,B1, C1, D1 and E1), top view (A2,B2, C2, D2 and E2) and cross sections of 3D printed tablets based on Eudragit RL: RS: 100:0, 75:25, 50:50, 25:75 and 0:100 respectively.

Fig. 8 In vitro release of theophylline from 3D printed tablets based on Eudragit RL: RS: 100:0, 75:25, 50:50, 25:75 and 0:100 using $\mathrm{pH}$-change USPII dissolution test ( $\mathrm{pH} 1.2$ for 2 hours followed by $\mathrm{pH}$ 6.8 for 10 hours, $\mathrm{n}=3, \pm \mathrm{SD}$ ). 


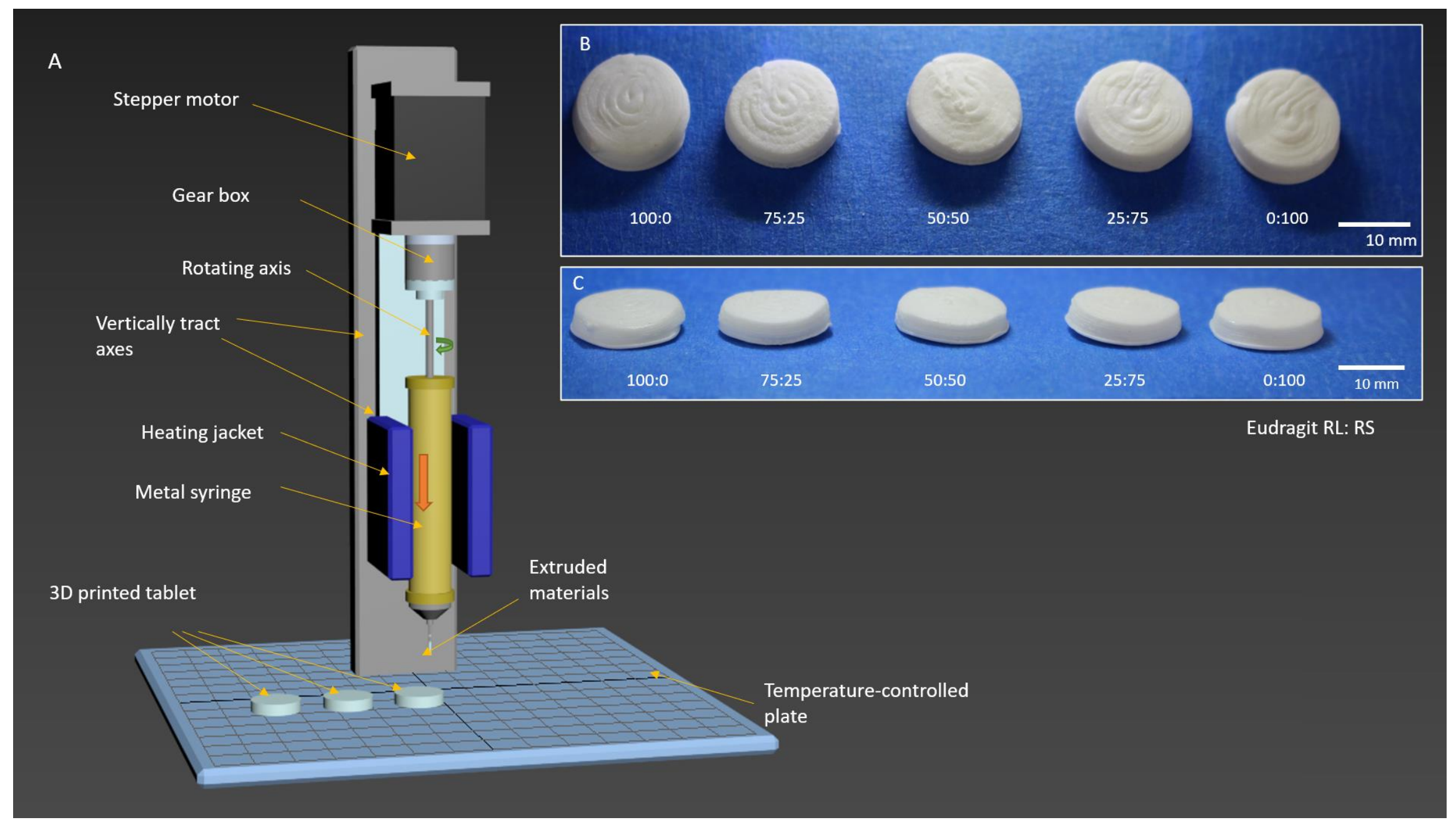

Fig. 1. (A) Set-up for semi-solid extrusion 3D printing. (a) The printer is equipped with a metal syringe surrounded by temperature-controlled heating jacket. The syringe is fitted with a luer-lock stainless steel needle (G18), (b) The pharmaceutical ink (compressed powder) is added. The ink is then extruded by a piston pushed by computer-controlled stepper motor equipped with gear to produce (c) 3D printed tablet. (B) Top and (C) side photographs of 3D printed tablets based on Eudragit RL: RS: 100:0, 75:25, 50:50, 25:75 and 0:100. 
A

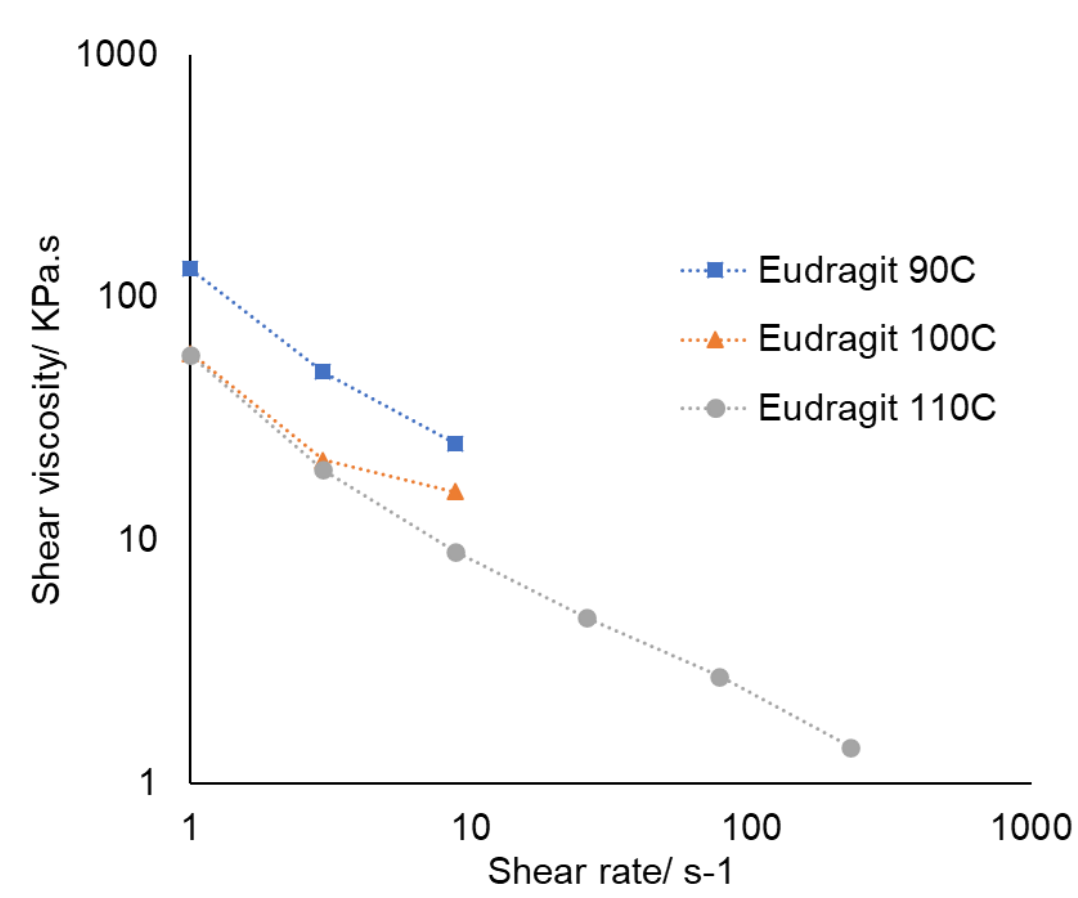

B

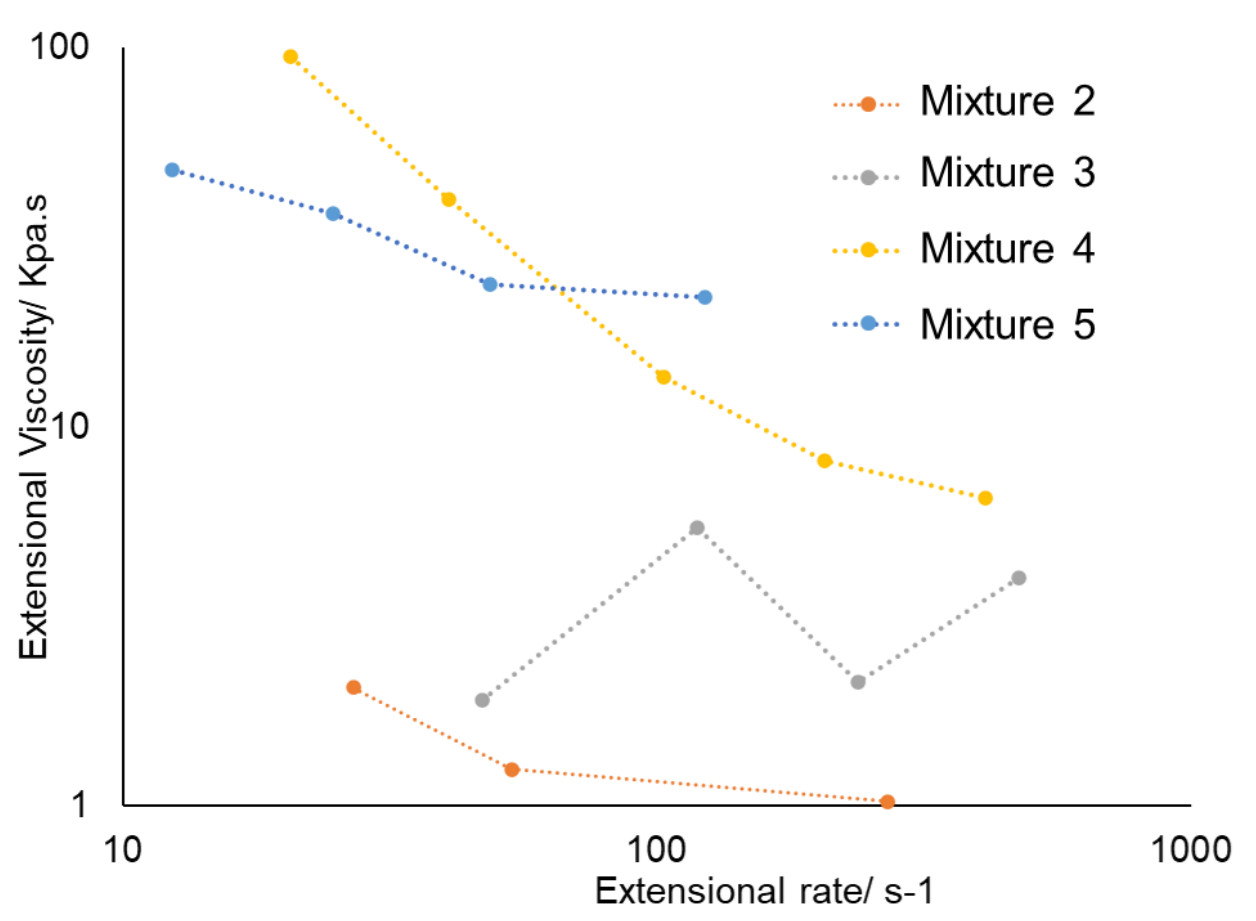

Fig. 2 (A) Shear viscosity of Eudragit RL 100 at temperature range of $90-110^{\circ} \mathrm{C},(\mathbf{B})$ Extensional viscosity data of mixtures. 


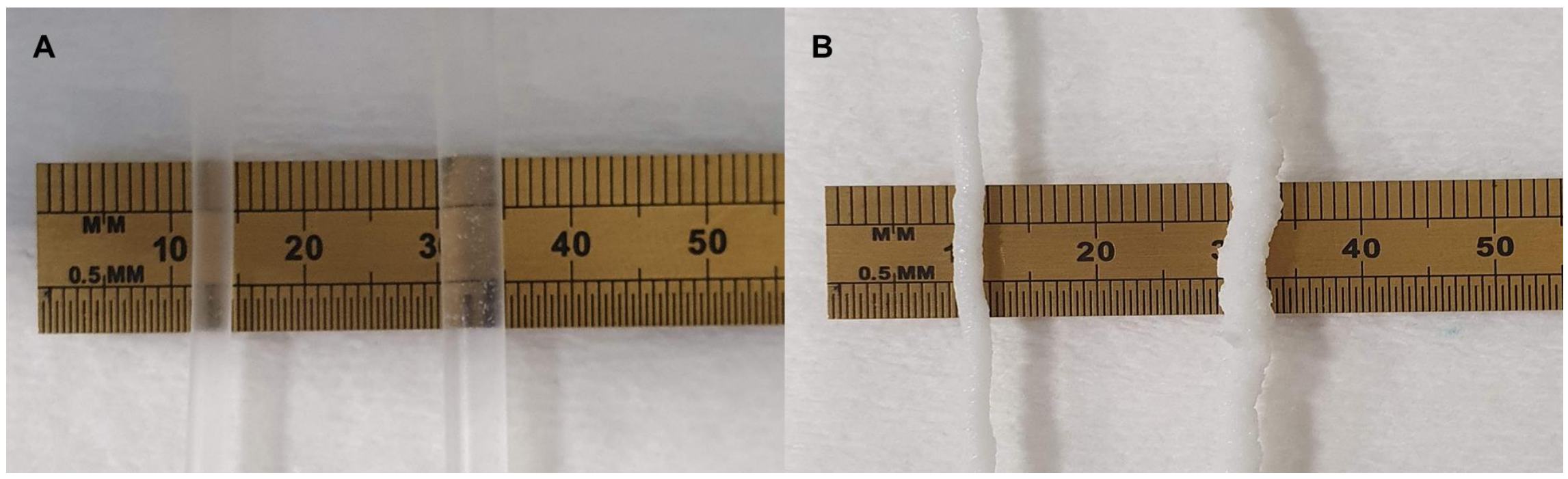

Fig. 3 (A) Eudragit RL extruded at $110^{\circ} \mathrm{C}$ using a long die (left, $\mathrm{d}=3.5 \mathrm{~mm}$ ), and an orifice die (right, $\mathrm{d}=5 \mathrm{~mm}$ ) (B) Eudragit RL formulation extruded at $90^{\circ} \mathrm{C}$ using long die (left, $\mathrm{d}=1.5 \mathrm{~mm}$ ), and an orifice die (right, $\mathrm{d}=4 \mathrm{~mm}$ ). 


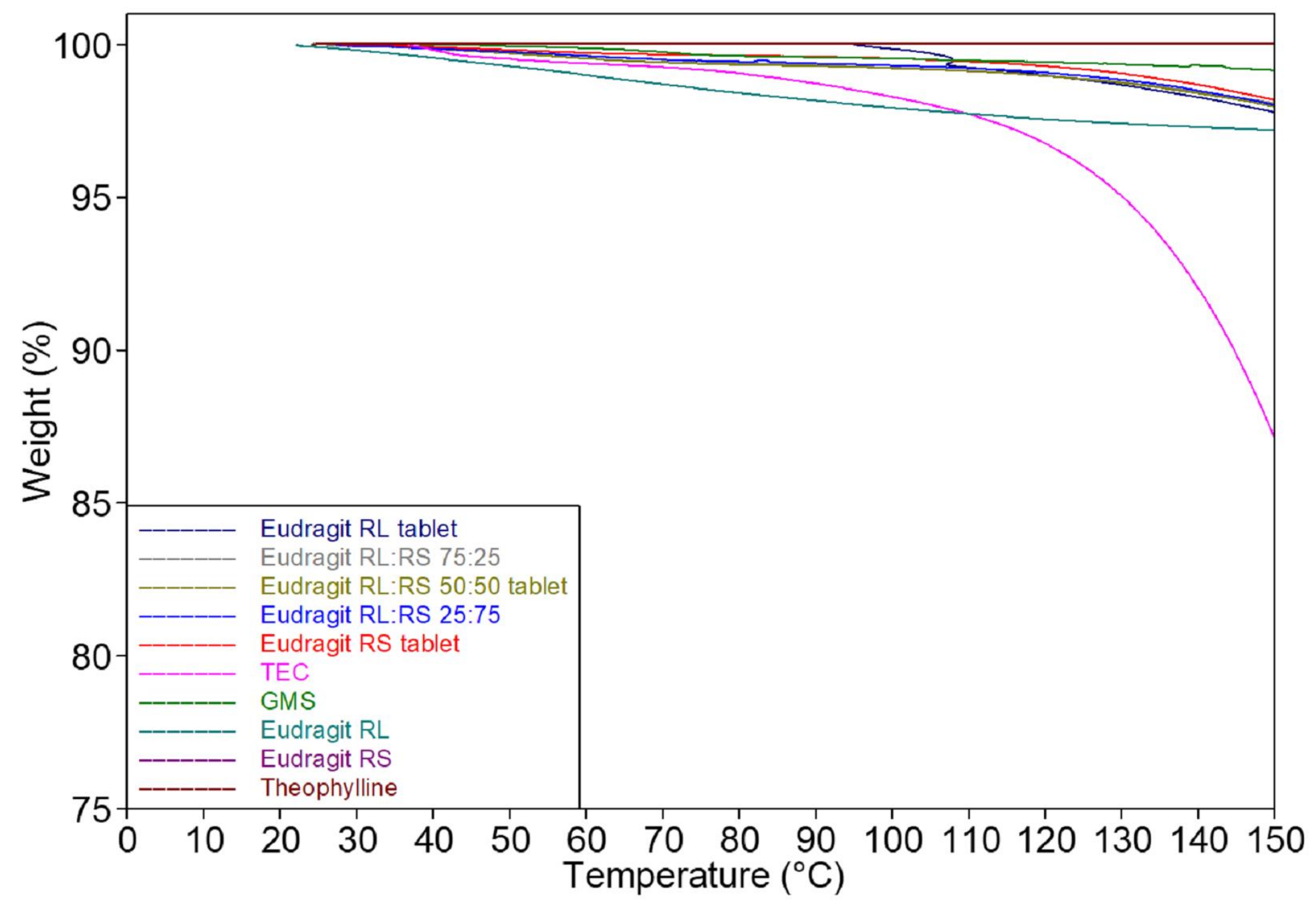

Fig. 4 TGA thermal degradation profiles of raw theophylline, Eudragit RL, Eudragit RS, TEC, GMS, and 3D printed tablets based on Eudragit RL: RS: 100:0, 75:25, 50:50, 25:75 and 0:100. 


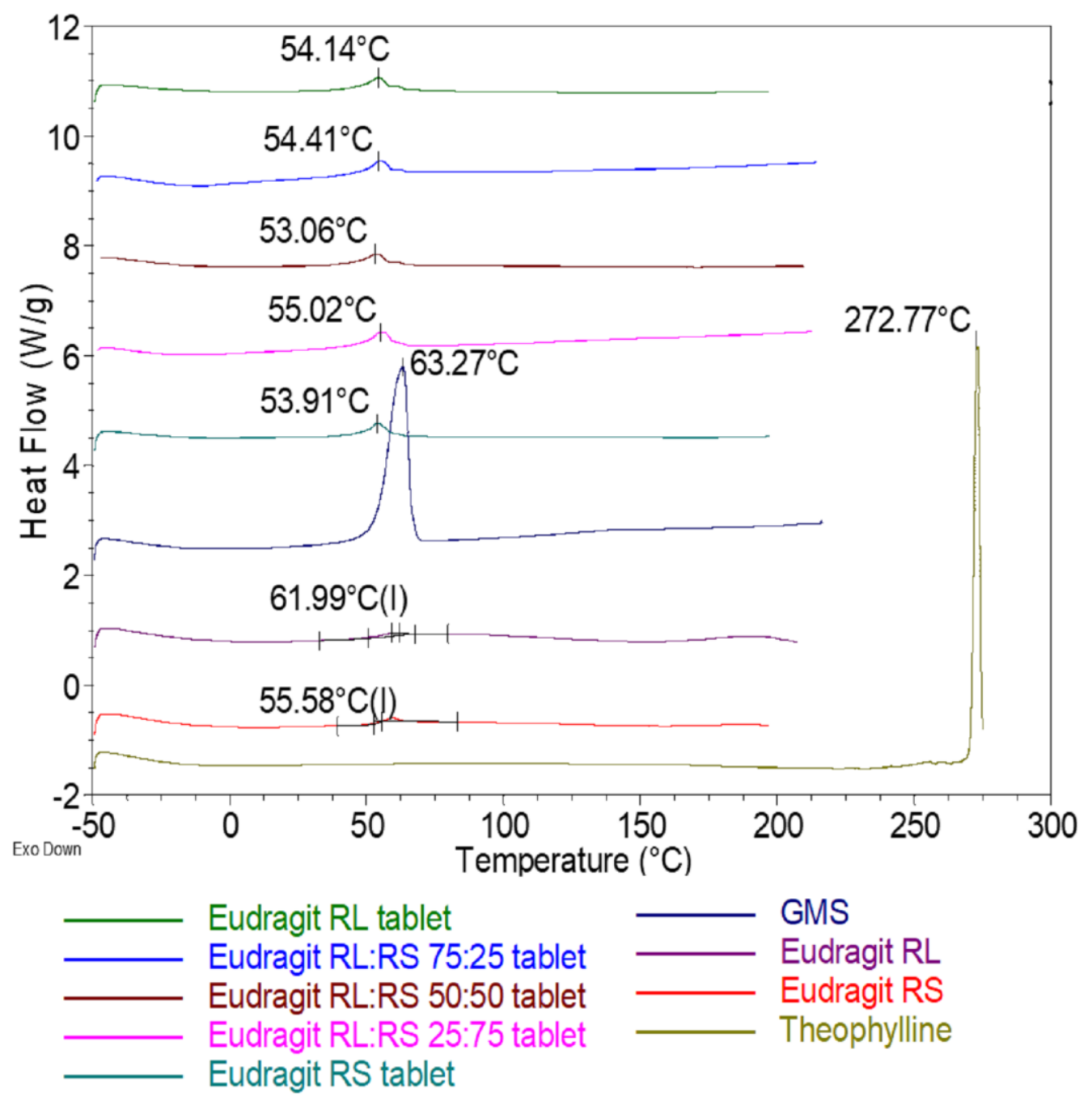


Fig. 5 DSC thermograph of raw theophylline, Eudragit RL, Eudragit RS, TEC, GMS, and 3D printed tablets based on Eudragit RL: RS: 100:0, 75:25, 50:50, 25:75 and 0:100.

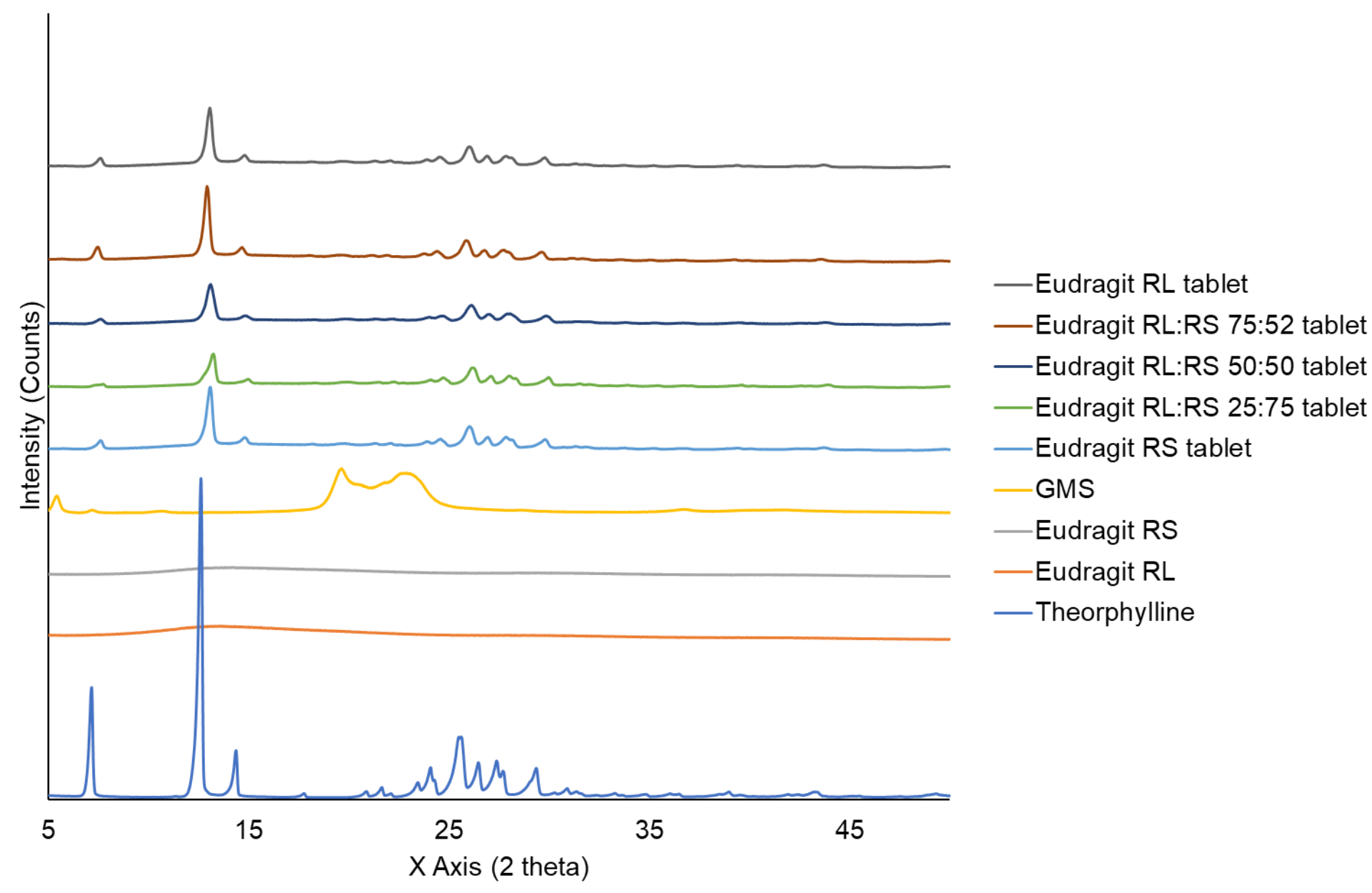

Fig. 6 XRPD of raw theophylline, Eudragit RL, Eudragit RS, TEC, GMS, and 3D printed tablets based on Eudragit RL: RS: 100:0, 75:25, 50:50, 25:75 and 0:100. 



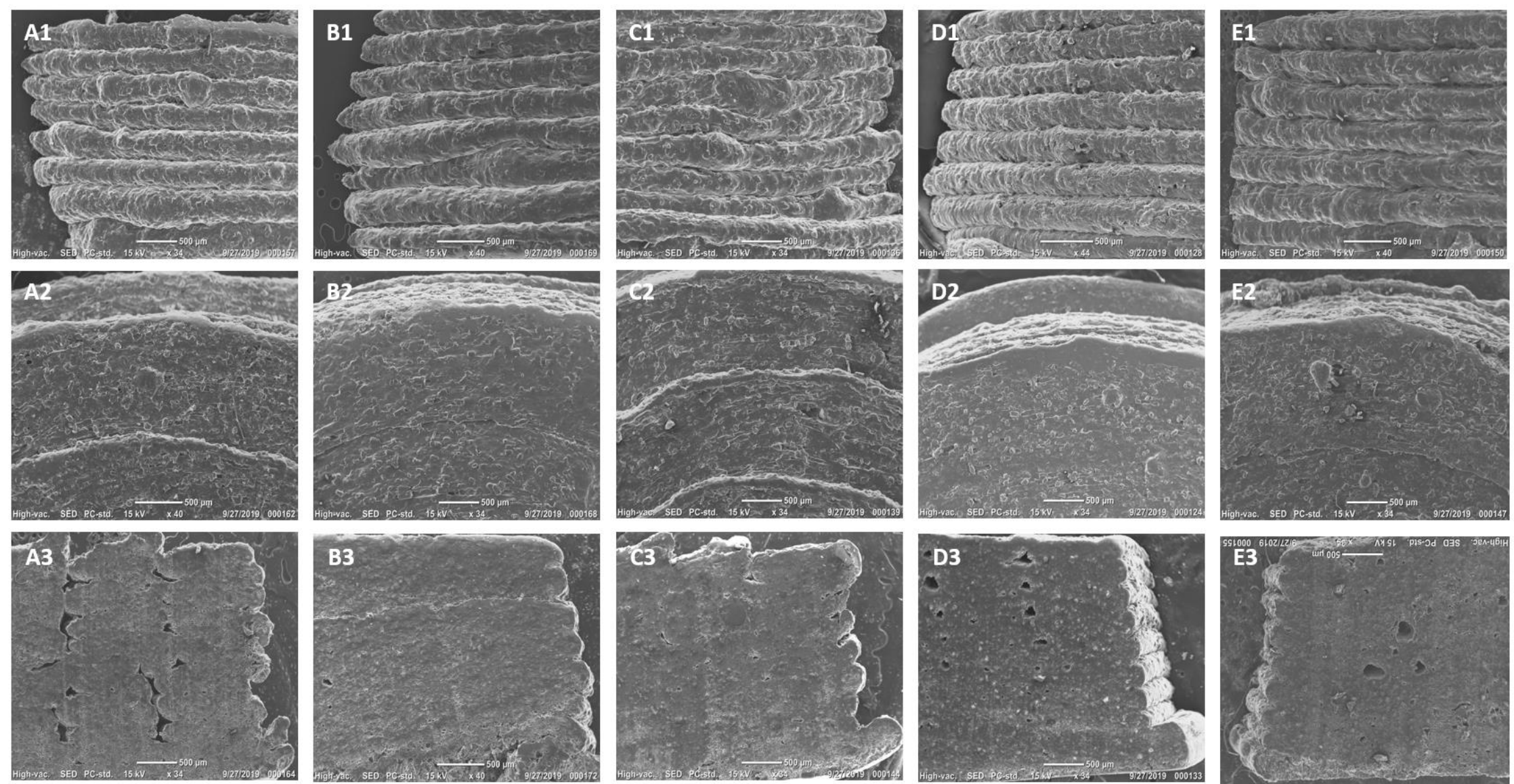

100:0

75:25

50:50

25:75

$0: 100$

Eudragit RL: RS

Fig. 7 SEM images of side-view (A1,B1, C1, D1 and E1), top view (A2,B2, C2, D2 and E2) and cross sections of 3D printed tablets based on Eudragit RL: RS: 100:0, 75:25, 50:50, 25:75 and 0:100 respectively. 


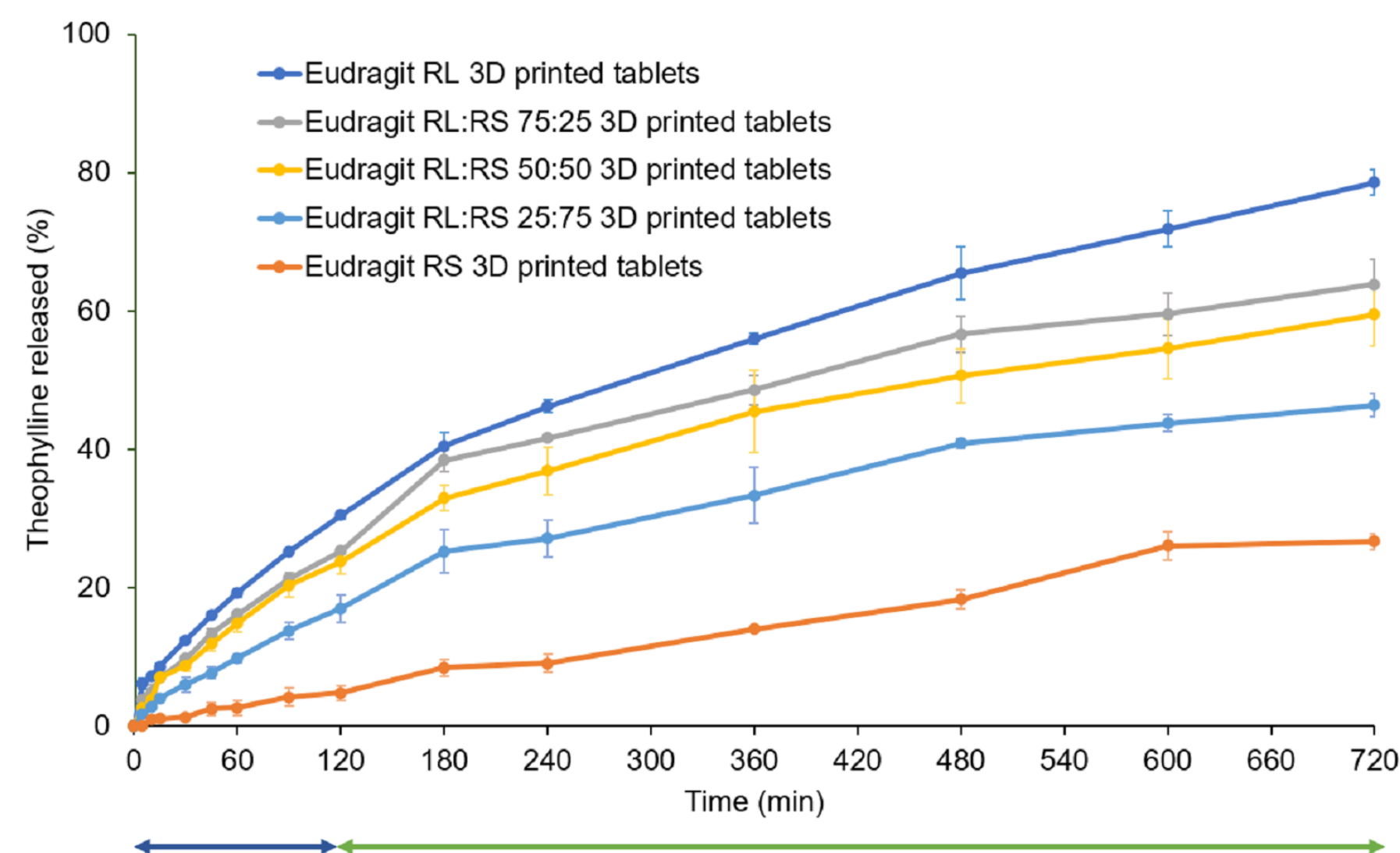

pH 1.2

pH 6.8

Fig. 8 In vitro release of theophylline from 3D printed tablets based on Eudragit RL: RS: 100:0, 75:25, 50:50, 25:75 and 0:100 using pH-change USPII dissolution test ( $\mathrm{pH} 1.2$ for 2 hours followed by $\mathrm{pH} 6.8$ for 10 hours, $\mathrm{n}=3, \pm \mathrm{SD}$ ). 
Table II Samples analysed in the rheology studies

\begin{tabular}{llllll}
\hline Sample nr & Eudragit RL & GMS & TEC & Theophylline & Temperature ( $\left.{ }^{\circ} \mathbf{C}\right)$ \\
\hline $\mathbf{1}$ & $100 \%$ & & & & $90,100,110$ \\
$\mathbf{3}$ & $40 \%$ & $8 \%$ & $12 \%$ & $40 \%$ & 90 \\
$\mathbf{4}$ & $77 \%$ & $23 \%$ & & 90 \\
$\mathbf{5}$ & $43.5 \%$ & $13 \%$ & $43.5 \%$ & 90 \\
\hline
\end{tabular}


Table II Composition and printing temperature of 3D printed tablets

\begin{tabular}{|c|c|c|c|c|c|c|c|}
\hline Tablets/Ingredients & Eudragit RL & Eudragit RS & GMS & TEC & Theophylline & $\begin{array}{l}\text { Printing } \\
\text { Temperature } \\
\left({ }^{\circ} \mathrm{C}\right)\end{array}$ & $\begin{array}{l}\text { Plate } \\
\text { Temperature } \\
\left({ }^{\circ} \mathrm{C}\right)\end{array}$ \\
\hline Eudragit RL 3D printed tablets & $40 \%$ & - & $8 \%$ & $12 \%$ & $40 \%$ & 90 & 45 \\
\hline Eudragit RL:RS 75:25 3D printed tablets & $30 \%$ & $10 \%$ & $8 \%$ & $12 \%$ & $40 \%$ & 110 & 45 \\
\hline Eudragit RL:RS 50:50 3D printed tablets & $20 \%$ & $20 \%$ & $8 \%$ & $12 \%$ & $40 \%$ & 105 & 45 \\
\hline Eudragit RL:RS 25:75 3D printed tablets & $10 \%$ & $30 \%$ & $8 \%$ & $12 \%$ & $40 \%$ & 95 & 45 \\
\hline Eudragit RS 3D printed tablets & - & $40 \%$ & $8 \%$ & $12 \%$ & $40 \%$ & 80 & 40 \\
\hline
\end{tabular}


Table III Solubility parameters of raw materials $\left(\mathrm{MPa}^{1 / 2}\right)$

\begin{tabular}{lllll}
\hline Excipient name & $\boldsymbol{\delta D}$ & $\boldsymbol{\delta P}$ & $\boldsymbol{\delta H}$ & $\boldsymbol{\delta} \mathbf{T}$ \\
\hline Eudragit RL & 17 & 11 & 4.2 & 20.7 \\
Theophylline & 19.7 & 15.5 & 10.5 & 27.1 \\
GMS & 16.2 & 4.2 & 10.3 & 19.7 \\
TEC & 16.8 & 6 & 10.1 & 20.5 \\
\hline
\end{tabular}


Table IV Dimensions, weight, friability, crushing strength, disintegration time drug contents and doses of 3D printed tablets.

\begin{tabular}{|c|c|c|c|c|c|c|c|c|}
\hline \multirow[t]{3}{*}{ 3D printed tablets } & \multicolumn{2}{|l|}{ Dimensions } & \multicolumn{2}{|l|}{ Weight } & \multirow{3}{*}{$\begin{array}{l}\text { Friability } \\
(\%)\end{array}$} & \multirow{3}{*}{$\begin{array}{l}\text { Crushing } \\
\text { strength } \\
\text { (N) }\end{array}$} & \multirow{3}{*}{$\begin{array}{l}\text { Drug contents (\%) } \\
( \pm \mathrm{SD})\end{array}$} & \multirow{3}{*}{$\begin{array}{l}\text { Dose (mg) } \\
( \pm \text { SD })\end{array}$} \\
\hline & Diameter & Height & Average & SD\% & & & & \\
\hline & mm $( \pm \mathrm{SD})$ & $\mathbf{m m}( \pm \mathrm{SD})$ & $\mathbf{m g}( \pm \mathrm{SD})$ & & & & & \\
\hline Eudragit RL & $13 \pm 0.1$ & $3 \pm 0.1$ & $457.3 \pm 7.9$ & $1.7 \%$ & $0.01 \%$ & $339.4 \pm 0.4$ & $94.65 \pm 1.44$ & $183.3 \pm 3.65$ \\
\hline Eudragit RL:RS 50:50 & $12.7 \pm 0.2$ & $2.7 \pm 0.1$ & $449.4 \pm 5.5$ & $1.2 \%$ & $0.02 \%$ & $340.4 \pm 4.5$ & $97.86 \pm 1.44$ & $173.23 \pm 15.29$ \\
\hline Eudragit RS & $13 \pm 0.2$ & $2.8 \pm 0.2$ & $442 \pm 5.3$ & $1.2 \%$ & $0.02 \%$ & $342.3 \pm 1.1$ & $98.19 \pm 4.7$ & $178.5 \pm 4.62$ \\
\hline
\end{tabular}

